\title{
SELF-SUFFICIENCY IN MANUFACTURE OF APIS AND INTERMEDIATES IS A NECESSITY FOR THE INDIAN PHARMACEUTICAL INDUSTRY
}

Dear Reader,

Active Pharmaceutical Ingredients (APIs) are key raw materials to produce pharmaceutical finished dosage forms like tablets, capsules, syrups, ointments etc. Swift growth in new innovations is prodding the interest for generic active pharmaceutical ingredients manufacturers worldwide with the expanded import of key starting materials (KSMs) and building blocks from the emerging markets.

The focus of Indian pharmaceutical industry in last two decades has moved towards finished formulations, ignoring in-house manufacture of APIs to a considerable extent.

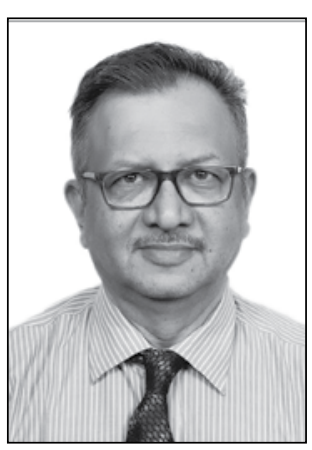

India's expanding reliance on imports from China in particular and other countries for some key starting materials that go into the making of various basic active pharmaceutical ingredients or bulk actives has been referred to as a reason of worry for policymakers. Thus there is a pressing need to reduce the dependence on China in particular for imports of certain basic active pharmaceutical ingredients and several key starting materials and building blocks.

According to Boston Consulting Group (BCG) and Confederation of Indian Industry (CII) report, the major medications for which APIs originate from China include painkillers like paracetamol; anti-infectives like Amoxicillin and Ampicillin, Cephalexin, Cefaclor, Ciprofloxacin, Ofloxacin, Levofloxacin, first line antidiabetics like Metformin andanti-ulceratives like Ranitidine.

According to BCG-CII report published in 2014, there are no local manufacturers for various medications like Penicillin-G and its derivatives 6-Aminopenicillanic Acid, making our country dependent on import of KSMs used in essential antibiotics, including semi-synthetic penicillins and cephalosporins. More than 75 percent of India's KSMs import originate from China. This is a reason for worry as perceived by pharmaceutical experts of India.

Indian pharmaceutical manufacturers have now realised that they have to develop a system to decrease its dependence on import of various active pharmaceutical ingredients, key starting intermediates and building block chemicals.

India has demonstrated its capacities to manufacture generic formulations, but over-dependence on China is a threat to the Indian pharmaceutical industry, as any interruption in supply can seriously affect the pharmaceutical sector and pose a risk to the huge Indian population

In the last two decades, there were no serious efforts to bring industry and institute together, in India. It is a general belief that industry is not fully aware of what they can benefit from institute linkage.

Meetings between policy makers and representatives from CSIR Laboratories and Universities like Institute of Chemical Technology, Mumbai and University of Hyderabad took place in 2017 in Mumbai, Hyderabad and New Delhi, to explore strategies to reduce dependence on import by Indian Pharmaceutical Industry. The main topics of discussion were: What areas India should exactly focus on? Which are the KSMs and APIs that selected laboratories or universities can synthesize? Challenge/s faced in terms of yields or purity or effluents or raw material price etc.

Development of plant friendly, cost effective technology and /or effluent management etc., generating a competitive advantage for the particular product was regarded as the primary goal of these discussions. The meetings with policy makers at government officials exposed a huge opportunity for industry collaborating with institutes, for national progress. 